\title{
ОБ ОБОСНОВАННОСТИ КВАЛИФИКАЦИИ ПРЕСТУПЛЕНИЙ ПРИ РАССМОТРЕНИИ УГОЛОВНОГО ДЕЛА В ОСОБОМ ПОРЯДКЕ
}

\begin{abstract}
Аннотация: При рассмотрении уголовного дела в особом порядке возникает вопрос об основаниях квалификаичи преступления: может ли она быть обоснована не только совокупностью обстоятельств дела и составом преступления, но и договоренностями сторон с иелью стимулирования обвиняемого (подозреваемого) к компромиссу. В статье указанная проблема исследуется с учетом правовой природы рассматриваемого института, которая представляется не столь однозначной за счет нерешенности вопроса о возможности его определения в качестве сделки (договора). В статье применены общенаучные и частнонаучные методы познания. К числу последних относятся, в частности, формально-юридический, сравнительно-правовой, системно-структурный методы. В результате исследования автором признается необходимость определения и легального закрепления указанного института как сделки в связи с наличием в нем признаков сделки (договора), характеризующих данное понятие в частном праве, а также с учетом соответствующего уголовно-процессуального опыта зарубежных стран. Исходя из этого, а также принимая во внимание цели института особого порядка -ускорение рассмотрения уголовного дела и (или) содействие правосудию - при принятии решения о применении того или иного вида особого порядка следует допустить возможность квалификации деяния на основании достигнутой договоренности. Однако в данном случае необходимо придавать особое значение обеспечению законности принятия всех юридически значимых решений по применению соответствующей процедуры и обеспечению обвиняемому (подозреваемому) права на защиту.
\end{abstract}

Ключевые слова: Особый порядок судопроизводства, досудебное согламение, сокращенное дознание, квалификаиия преступлений, принцип законности, принцип целесообразности, обоснованность обвинения, признание вины, доказывание, уголовно-проиессуальная сделка.

Abstract: During the hearing of a criminal case with accelerated prosecution there is a question of the bases of qualification of a crime, whether it may be proved not only by set of facts of the case and components of crime, but also agreement between the sides for the purpose of stimulation of the accused (suspect) to reach a compromise. This work examines this issue taking into account the legal nature of the considered institution, which seems somewhat ambiguous because of the unresolved issue of a possibility of its definition as a deal (agreement). The author uses general scientific and private methods of cognition, including methods of formal legal, legal comparative, systemic and structural analysis. As a result of the research the author acknowledges the necessity to define and formalize this institution as a "deal", because of existence of signs of a deal (agreement), which characterize this concept in private law, and also due to coinciding criminal procedure experience of foreign countries. Proceeding from it, and also in view of the purposes of this institution - acceleration of consideration of criminal case and (or) assistance to justice - in making decision on application of some type of special process, it is necessary to allow for the possibility of qualification of the crime on the basis of the reached agreement. However in this case it is necessary to attach special significance to the legality of making of all legally valid decisions on application of this procedure and ensuring the right for protection for the accused (suspect).

Keywords: Confession, validity of charge, principle of expediency, principle of legality, qualification of crimes, expedited investigation, plea deal, accelerated prosecution, proving, plea bargain.

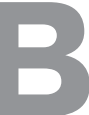

постсоветском законодательстве утверждение идеи об ускорении, упрощении и удешевлении судопроизводства связано с развитием института особого порядка судебного разбирательства. Уголовно-процессуальный кодекс Российской Федерации (далее - УПК РФ), по состоянию на время принятия [1], закреплял единственную форму этого института - особый порядок принятия судебного решения при согласии обвиняемого с предъявленным обвинением. Учитывая его востребованность (к 2009 г. уже 50,3 \% уголовных дел рассматривалось в особом порядке [2]), а также преследуя цель более эффективного расследования тяжких и особо тяжких групповых преступлений, законодатель пошел дальше, включив в 2009 г. в УПК РФ совокупность норм об особом порядке принятия судебного решения при 
заключении досудебного соглашения о сотрудничестве (именно таким образом поименована глава 40.1, несмотря на некоторые расхождения с фактическим её содержанием). Чуть позже последовал следующий шаг в данном направлении: в 2013 г. появилась третья разновидность особого порядка судебного разбирательства, которая имеет место при производстве дознания в сокращенной форме.

Каждый вид особого порядка судебного разбирательства имеет свои индивидуальные отличительные особенности, и весьма существенные. Однако в целом они представляют собой различные проявления упрощенного порядка судопроизводства, общие начала которого составляют: признание лицом, подвергаемым уголовному преследованию, своей вины (или согласие с предъявленным обвинением), его волеизъявление на применение упрощенной судебной процедуры и в результате - проведение судебного заседания без судебного следствия и назначение «льготного» наказания.

Унифицированный особый порядок судопроизводства может быть распространен также на стадию квалификации преступлений. Однако вопросы о правилах квалификации преступлений, процессуальных особенностях квалификационных процессов и их последствий в рамках особых порядков судебного разбирательства мало изучены и не обеспечены судебными позициями. Чтобы ситуация в этом отношении изменилась, необходимо допустить вывод, что квалификация преступления обосновывается не только совокупностью обстоятельств дела и составом преступления, но и договоренностями с целью стимулирования обвиняемого (подозреваемого) к компромиссу. Под договаривающимися сторонами в этом случае понимаются государство (в зависимости от вида особого порядка решение принимает либо суд (гл. 40 УПК РФ), либо участники процесса со стороны обвинения - прокурор (гл. 40.1 УПК РФ), дознаватель (гл. 32.1 УПК РФ)), а в некоторых случаях также потерпевший (гл.гл. 40, 32.1 УПК РФ), и с противоположной стороны - лицо, подвергаемое уголовному преследованию.

При инициировании применения особого порядка судебного разбирательства обвиняемый (подозреваемый) принимает на себя серьезные обязательства, связанные с отказом от презумпции невиновности и отчасти права на защиту, и вправе рассчитывать на минимизацию негативных последствий совершения преступления за счет смягчения не только будущего наказания, но и уголовно-правовой оценки содеянного. Решения о квалификации для лица, совершившего преступление, не менее важны, чем наказание, при любом порядке судопроизводства. Выводы о квалификации содеянного влияют не только на вид и размер назначаемого наказания, но и на возможность освобождения от уголовной ответственности и наказания (условного и безусловного), также обусловливают сроки судимости. Кроме того, квалификация преступления является предпосылкой правильного применения ряда уголовно-процессуальных положений: о мерах пресечения в отношении подозреваемого (обвиняемого), формах расследования, подследственности и подсудности уголовного дела. То, как преступное деяние было квалифицировано, важно и по завершению уголовных правоотношений при последующей реализации иных прав лица, в частности, избирательных, трудовых (в некоторых случаях трудовых прав членов семьи).

Очевидно, что распространение процедур особого порядка судопроизводства на стадию квалификации преступлений предполагает изменение традиционных представлений о целях квалификационных решений. Кроме цели установления предусмотренного уголовным законом состава преступления в совершенном деянии, выделяется цель поощрения к совершению положительных посткриминальных поступков. Такое решение вытекает из понимания юридической сути института особого порядка судебного разбирательства, критериальное значение для которого имеет идея о договорной природе особых порядков. Сделка (договор) - институт частного права, однако это вовсе не препятствует его эффективной реализации в процессуальных (публичных) отраслях. Примером могут служить, в частности, соглашение о подсудности, третейское (арбитражное) соглашение о примирительной процедуре, мировое соглашение в гражданско-процессуальном праве. Эти соглашения являются проявлением проходящих в отечественной правовой системе процессов конвергенции частного и публичного права, которые в настоящее время очень актуальны по причине нерешенности сложнейшей задачи - определения границ частного и публичного, вызванной сочетанием в едином институте, казалось бы, несовместимых явлений [3; 4; 5, с. 28-39].

С позиции гражданского права сделками признаются действия граждан и юридических лиц, направленные на установление, изменение или прекращение прав и обязанностей (ст. 153 Гражданского кодекса Российской Федерации). Возникают ли какие-либо права и обязанности у сторон при взаимодействии в особом порядке в условиях уголовного процесса? Полагаем, что да. Стороной защиты реализуется право на признание вины (в соответствии со статьями гл. 40.1 УПК РФ - еще сотрудничество), а также 


\section{Право и политика $11(203) \cdot 2016$}

упрощение порядка судебного разбирательства (а в случаях, учтенных в статьях гл. 32.1 УПК РФ - еще и упрощение предварительного расследования) и наказание в сниженных пределах. Перечисленным правам стороны защиты корреспондируют соответствующие обязанности государства. При этом права стороны защиты не исключают её обязательств, которые разнятся в специальных видах особого порядка. В некоторых случаях даже устанавливается ответственность за неисполнение соответствующих обязанностей (например, согласно ст. 63.1 УК РФ за нарушение обязательств, указанных в соглашении о сотрудничестве, обвиняемого (подозреваемого) «наказывают» недопустимостью назначения наказания ниже низшего предела по ст. 64 УК РФ).

Таким образом, отдельные признаки сделки в институте особого порядка судопроизводства присутствуют. Интересен опыт применения смежного института - сделок о признании вины в иностранных государствах.

Комплексно оценивая опыт зарубежных стран по использованию различных компромиссных процедур в уголовном процессе, отметим, что практика иностранных государств выработала множество вариантов их применения, которые способствуют более быстрому и финансово менее обременительному для государственного бюджета разрешению уголовных дел. Однако далеко не все они являются сделками.

Одна тенденция - заключение полноценного соглашения, устанавливающего права и обязанности как обвиняемого, так и стороны обвинения. Наиболее показательным примером тому служит опыт США $[6$, с. $96 ; 7$, с. $8 ; 8$, с. 52-53]. Исторически именно в уголовно-процессуальной системе США впервые зародилась и укоренилась практика заключения сделок в наиболее «чистом» виде. В американских сделках представлена такая модель отношений, при которой обвиняемый всегда может гарантированно рассчитывать на смягчение обвинения или отказ прокурора от обвинения в обмен на сотрудничество или признание вины. Причем положения соглашения являются обязательными для обеих сторон и тем самым характеризуют такие отношения как полноценный договор.

Другая тенденция свойственна странам континентальной Европы [9, с. 30-31; 10, с. 6, 14]. В соответствии с ней сотрудничество обвиняемого (подозреваемого) или признание им вины и согласие на упрощенную процедуру судопроизводства является по своей сути смягчающим наказание обстоятельством. Применение соответствующих норм закона отнесено к судейскому усмотрению. Таким образом, сторона обвинения не имеет достаточных правовых гарантий, чтобы обсуждать с обвиняемым условия соглашения на равных и предложить ему хотя бы назначение гарантированного определенного наказания, не говоря уже об изменении квалификации деяния. Договорной природы такого института не усматривается.

Концептуальное отличие первого из двух рассмотренных вариантов конструирования сделок о признании вины выражается в способности стороны обвинения быть самостоятельной и независимой при заключении соглашения, принимать решения о его условиях, в том числе брать на себя определенные обязательства, исходя из идеи целесообразности, что проявляется в возможности переквалифицировать деяние на норму, предусматривающую ответственность за менее тяжкое преступление, исключить отдельные эпизоды преступной деятельности из итоговой квалификации, с целью стимулирования лица к сотрудничеству $[8$, с. 55-61,95; 11$]$.

Самое важное в такой сделке - ее двусторонний взаимообязательный характер. У стороны обвинения для этого есть широкий арсенал средств, посредством которых она может предложить обвиняемому желаемое в обмен на признание вины либо на предоставление полезной для правосудия информации. Полагаем, что именно это обстоятельство является фундаментом для построения института процессуального договора.

У идеи договорной природы российских особых порядков судебного разбирательства есть значительное число сторонников в научной среде. Однако в большинстве своем ученые опасаются признавать наличие полноценного договора в российском уголовном процессе, аргументируя это как раз отсутствием вышеназванного критерия - свободы распоряжения обвинением. В частности, Г. И. Петрухин поясняет, что заключению сделки всегда предшествуют переговоры прокурора с защитником и обвиняемым при участии судьи. При этом имеют место определенные договоренности касательно квалификации преступления, а также будущего вида, размера и срока наказания, но это недопустимо в рамках действующего законодательства [12]. Иначе говоря, первичными при реализации сделки являются условия договора, а не нормы закона, что несвойственно особому порядку судебного разбирательства [13, с. 37].

Указанные доводы являются убедительными и не позволяют однозначно определять российский особый порядок судопроизводства как договор. Действительно, свобода сторон в определении условий сотрудничества (взаимодействия) в особом порядке не легализована. Вместе с тем утверждать, что в этом институте отсутствуют иные признаки сделки, в том числе в сфере квалификации преступлений, 
тоже нельзя. Действующее уголовно-процессуальное законодательство все же не исключает квалификацию преступления без точного соответствия с обстоятельствами дела и составом преступления. Это наиболее очевидно проявляется в нормах о проведении дознания в сокращенной форме.

Дело в том, что окончательной при производстве дознания в сокращенной форме (а также при дальнейшем постановлении приговора в судебном разбирательстве) становится квалификация преступления, установленная на стадии возбуждения уголовного дела (которая по большей части включает оперативную непроцессуальную деятельность). В научной среде безоговорочно признается, что квалификация преступления на данном этапе всегда носит предварительный, ориентировочный характер; здесь происходит установление общей принадлежности деяния к преступлению и по указанным объективным причинам постоянно возникают квалификационные ошибки [14, с. 56-57]. По мнению А. И. Рарога, это даже не квалификация преступлений, а квалификационная версия юридической сущности совершенного общественно опасного деяния [15, с. 18]. Тем не менее, при производстве дознания в сокращенной форме эта «квалификационная версия» зачастую становится окончательным обвинением.

При возбуждении уголовного дела в рассматриваемом случае фиксируется квалификация преступления, с которой соглашается подозреваемый и которую обещает не оспаривать. Однако она основана лишь на данных, которые послужили основанием для возбуждения дела (даже не являющихся доказательствами, зачастую полученных в рамках непроцессуальной деятельности). Тем не менее, законодатель в ч. 7 ст. 316 УПК РФ определил, что судья при постановлении обвинительного приговора в особом порядке должен убедиться, что обвинение, с которым согласился подсудимый (включая квалификацию преступления), подтверждено доказательствами. Следует понимать, что в данном случае у дознавателей нет времени, мотивации и правовых средств для сбора существенной доказательственной базы (в ст. 226.5 УПК РФ ограничен предмет доказывания и прямо разрешено не проводить многих следственных действий и не заниматься полноценным поиском доказательственной информации) [16; 17]. В этой связи рассматриваемое требование закона о проверке судом обоснованности обвинения видится «мертвым» и неисполнимым, и, вероятно, имеет целью «встроить»в закон деятельность по отправлению правосудия, основанную в большей степени на признании вины подозреваемым (обвиняемым).
Не только при проведении дознания в сокращенной форме, но и при любом ином особом порядке судопроизводства ввиду отсутствия судебного следствия (или его существования в усеченном виде) проверить и подтвердить, что окончательная квалификация преступления основана на достаточной совокупности относимых, допустимых и достоверных доказательств, в суде невозможно. Характер упрощенных процедур, основанных на признании вины, свидетельствует об отступлении российского уголовного процесса от необходимости правильной квалификации преступления. Тем самым закон оставляет всё меньше препятствий для усиления диспозитивного начала в уголовном процессе и развития договорного потенциала особых порядков судебного разбирательства.

В условиях поддержанного законом невнимания суда к доказанности обвинения видится справедливой идея сторонников договорной природы особого порядка о допустимости «торга» между стороной обвинения и стороной защиты относительно оснований уголовной ответственности, возможности уступок по предмету, основаниям, объему уголовного иска, если это необходимо в интересах повышения эффективности оперативно-розыскной и процессуальной обвинительной деятельности [18, с. 17-18; 19, с. 223]. То есть, в качестве тактического приема стимулирования подозреваемого (обвиняемого) к даче признательных показаний и применению упрощенного порядка судопроизводства предлагается обещание ему (и последующее выполнение своего обещания) не вменять дополнительно в обвинение другие преступления, в совершении которых он также изобличен. Либо квалифицировать инкриминируемое преступление по более «мягкой» статье УК, чем та, которая может иметь место исходя из установленных обстоятельств содеянного.

Векторы уголовной политики меняются, и есть основания полагать, что стремление к упрощению, удешевлению и ускорению судопроизводства может привести к радикальному пересмотру, в том числе, процесса квалификации преступлений и появлению настоящей полноценной сделки в российском уголовном процессе. В этой связи примечательно рассуждение Н. Н. Апостоловой, касающееся востребованности идеи справедливой законности - целесообразного и разумного применения закона, обеспечивающего эффективную защиту интересов граждан, общества и государства. Действующее законодательство требует от правоприменителей, чтобы они руководствовались необходимостью наиболее эффективного и справедливого применения закона для защиты как публичных интересов, так и прав, свобод и законных интересов 


\section{Право и политика $11(203) \cdot 2016$}

человека [20, с. 29-30]. Поэтому представляется, что предоставление права распоряжения уголовным иском стороне обвинения, если это отвечает вышеуказанным целям, позволит оптимизировать процесс в упрощенных процедурах, будет способствовать повышению количества и качества взаимодействия и сотрудничества подозреваемых (обвиняемых) с правоохранительными органами, усилению защиты их прав и фактическому освобождению стороны обвинения от необходимости проведения полноценного расследования и доказывания обвинения.

Чтобы несколько примирить появившиеся упрощенные процедуры с действующими принципами уголовного права и процесса, необходимо уделить особое внимание обеспечению законности их проведения. В качестве одной из таких мер многими предлагается введение предварительного судебного контроля по соответствующим делам [21, с. 40-41; 22], как это сделано в некоторых зарубежных странах. Например, такая практика успешно существует в ФРГ, где в процедуру заключения т.н. «сделки о признании вины» обычно вовлекаются не только защитник и обвинитель, но и суд. По малозначительным делам защита ведет переговоры с обвинителем, и затем заключенная сделка одобряется судом. В более серьезных уголовных делах суд обязательно непосредственно участвует в обсуждении [7, с. 104-105]. Однако здесь возникает иного рода препятствие. Задача особого порядка судебного разбирательства - ускорить, упростить судопроизводство. А при рассмотрении судом вопроса, например, о законности ходатайства обвиняемого о применении особого порядка, заключенного соглашения о сотрудничестве, есть риски нейтрализовать весь положительный эффект от упрощения и затянуть процесс. В этой части идея внедрения подобного предварительного судебного контроля несовершенна и нуждается в доработке.

В существующих условиях полагаем, что особое внимание должно быть уделено не безусловности требования доказанности обвинения и истинности (обоснованности) квалификации преступления, а гарантированности добровольности и законности принятия всех решений, связанных с упрощенными процедурами. Необходимо обеспечить обвиняемому реализацию права на защиту и возможность на любом этапе предварительного расследования и судопроизводства вернуться к рассмотрению и разрешению дела в общем порядке. Особенно это касается случаев производства дознания в сокращенной форме и заключения досудебного соглашения о сотрудничестве, когда лицо признает вину порой на очень раннем этапе предварительного следствия при отсутствии достаточной доказательственной базы и соглашается с квалификацией преступления, которая с учетом полного установления обстоятельств дела может быть оценена как ухудшающая положение лица. По таким делам представляется целесообразным закрепить право лица только по окончании предварительного расследования подать ходатайство о рассмотрении его дела в особом порядке либо сделать соответствующую пометку о его согласии на особый порядок судебного разбирательства по предъявленному обвинению при ознакомлении с материалами уголовного дела.

\section{Библиография:}

1. Уголовно-процессуальный кодекс Российской Федерации от 18.12.2001 № 174-Ф3 // Парламентская газета, № 241-242, 22.12.2001, Российская газета, № 249, 22.12.2001, Собрание законодательства Российской Федерации, 24.12.2001, № 52 (ч. I), ст. 4921.

2. Судебная статистика. Официальный сайт Судебного Департамента при Верховном Суде Российской Федерации // URL: http://www.cdep.ru/index.php?id=79 (дата обращения: 08.04.2016).

3. Кленова Т.В. О совместимости публичного и частного интересов в уголовном праве // Уголовное право. 2006. № 2. С. 41 - 45.

4. Муратова Н.Г., Челышев М.Ю. О межотраслевой теории процессуальных соглашений: вопросы гражданского права, цивилистического и уголовного процесса // Вестник гражданского процесса. 2012. № 4. С. 10-27

5. Елисеев Н.Г. Процессуальный договор - М.: Статут, 2015. - 368 с.

6. Пиюк А.В. Типология современного уголовного процесса и проблемы применения упрощенных форм разрешения уголовных дел в судопроизводстве Российской Федерации: монография - М.: Юрлитинформ, 2013. - 264 с.

7. Turner Jenia L. Plea Bargaining across borders: criminal procedure. - Wolters Kluwer Law \& Business; New York : Aspen Publishers, 2009. - 294 c.

8. Dervan Lucian E. Bargained Justice: Plea Bargaining's Innocence Problem and the Brady Safety-Valve // Utah Law Review Forthcoming. 2012. P. 51-97.

9. Головко Л.В. Альтернативы уголовному преследованию как форма процессуальной дифференциации (современные тенденции развития). Автореф. дис. ... д-ра юрид. наук. М., 2003. 54 с.

10. Бахновский А. В. Сделка с правосудием: особенности англосаксонской и континентальной правовой традиции. Автореф. дис. ... канд. юрид. наук. Краснодар, 2008. 19 с.

11. Turner Jenia L. Prosecutors and Bargaining in Weak Cases: A Comparative View. // Erik Luna, Marianne Wade The prosecutor in transnational perspective. New York: Oxford University Press, 2012. C. 102-115. 
DOI: $10.7256 / 1811-9018.2016 .11 .18810$

При цитировании этой статьи сноска на dоі обязательна

Закон и правопорядок

12. Петрухин Г.И. Роль признания обвиняемого в уголовном процессе // Российская юстиция. 2003. № 2. С. 24-26.

13. Толкаченко А.А. Особый порядок судопроизводства-междисциплинарный институт // Российская юстиция. 2011. № 8. C. 36-39.

14. Кузнецова Н.Ф. Проблемы квалификации преступлений: Лекции по спецкурсу «Основы квалификации преступлений» - М.: Издательский Дом «Городец». 2007. - 336 с.

15. Рарог А.И. Настольная книга судьи по квалификации преступлений: практическое пособие-М.: Проспект, $2006 .-224$ с.

16. Кругликов А.П. Дополнение УПК РФ новой главой о дознании в сокращенной форме и некоторые проблемы дифференциации уголовного судопроизводства // Российская юстиция. 2013. № 7. С. 45-50.

17. Панокин А.М. Дознание в сокращенной форме // Актуальные проблемы российского права. 2014. № 5. С. 914-918.

18. Александров А.С., Кучин А.Ф., Смолин А.Г. Правовая природа института, регламентированного главой 40 УПК РФ // Российский судья. 2007. № 7. С. 16-18.

19. Лазарева В.А., Кувалдина Ю.В. Проблемы правового регулирования и применения института досудебного соглашения о сотрудничестве // Библиотека криминалиста: Научный журнал. Вып. 3 (4). 2012. С. 221-231.

20. Апостолова Н.Н. Целесообразность (дискреционность) в российском уголовном судопроизводстве. Автореф. дис. ... д-ра юрид. наук. М., 2010. 62 с.

21. Лазарева В.А. Легализация сделок о признании вины // Российская юстиция. 1999. № 5. С. 41-44.

22. Быков В.М., Быков А.М. Сторона защиты при заключении с прокурором досудебного соглашения о сотрудничестве // Российская юстиция. 2010. № 9. С. $18-22$.

\section{References (transliterated):}

1. Klenova T.V. O sovmestimosti publichnogo i chastnogo interesov v ugolovnom prave // Ugolovnoe pravo. 2006. № 2. S. 41 - 45.

2. Muratova N.G., Chelyshev M.Yu. O mezhotraslevoi teorii protsessual'nykh soglashenii: voprosy grazhdanskogo prava, tsivilisticheskogo i ugolovnogo protsessa // Vestnik grazhdanskogo protsessa. 2012. № 4. S. 10-27

3. Eliseev N.G. Protsessual'nyi dogovor - M.: Statut, 2015. - 368 s.

4. Piyuk A.V. Tipologiya sovremennogo ugolovnogo protsessa i problemy primeneniya uproshchennykh form razresheniya ugolovnykh del v sudoproizvodstve Rossiiskoi Federatsii: monografiya - M.: Yurlitinform, 2013. - 264 c.

5. Turner Jenia L. Plea Bargaining across borders: criminal procedure. - Wolters Kluwer Law \& Business; New York : Aspen Publishers, 2009. - 294 s.

6. Dervan Lucian E. Bargained Justice: Plea Bargaining's Innocence Problem and the Brady Safety-Valve // Utah Law Review Forthcoming. 2012. P. 51-97.

7. Golovko L.V. Al’ternativy ugolovnomu presledovaniyu kak forma protsessual'noi differentsiatsii (sovremennye tendentsii razvitiya). Avtoref. dis. ... d-ra yurid. nauk. M., 2003. 54 c.

8. Bakhnovskii A. V. Sdelka s pravosudiem: osobennosti anglosaksonskoi i kontinental'noi pravovoi traditsii. Avtoref. dis. ... kand. yurid. nauk. Krasnodar, 2008. $19 \mathrm{c}$.

9. Turner Jenia L. Prosecutors and Bargaining in Weak Cases: A Comparative View. // Erik Luna, Marianne Wade The prosecutor in transnational perspective. New York: Oxford University Press, 2012. S. 102-115.

10. Petrukhin G.I. Rol' priznaniya obvinyaemogo v ugolovnom protsesse // Rossiiskaya yustitsiya. 2003. № 2. S. 24-26.

11. Tolkachenko A.A. Osobyi poryadok sudoproizvodstva-mezhdistsiplinarnyi institut// Rossiiskaya yustitsiya. 2011. № 8. S. 36-39.

12. Kuznetsova N.F. Problemy kvalifikatsii prestuplenii: Lektsii po spetskursu «Osnovy kvalifikatsii prestuplenii»-M.: Izdatel'skii Dom «Gorodets». 2007. - 336 s.

13. Rarog A.I. Nastol'naya kniga sud'i po kvalifikatsii prestuplenii: prakticheskoe posobie- M.: Prospekt, 2006. - 224 s.

14. Kruglikov A.P. Dopolnenie UPK RF novoi glavoi o doznanii v sokrashchennoi forme i nekotorye problemy differentsiatsii ugolovnogo sudoproizvodstva // Rossiiskaya yustitsiya. 2013. № 7. S. 45-50.

15. Panokin A.M. Doznanie v sokrashchennoi forme // Aktual'nye problemy rossiiskogo prava. 2014. № 5. S. 914-918.

16. Aleksandrov A.S., Kuchin A.F., Smolin A.G. Pravovaya priroda instituta, reglamentirovannogo glavoi 40 UPK RF // Rossiiskii sud'ya. 2007. № 7. S. 16-18.

17. Lazareva V.A., Kuvaldina Yu.V. Problemy pravovogo regulirovaniya i primeneniya instituta dosudebnogo soglasheniya o sotrudnichestve // Biblioteka kriminalista: Nauchnyi zhurnal. Vyp. 3 (4). 2012. S. 221-231.

18. Apostolova N.N. Tselesoobraznost' (diskretsionnost') v rossiiskom ugolovnom sudoproizvodstve. Avtoref. dis. ... d-ra yurid. nauk. M., 2010. $62 \mathrm{~s}$.

19. Lazareva V.A. Legalizatsiya sdelok o priznanii viny // Rossiiskaya yustitsiya. 1999. № 5. S. 41-44.

20. Bykov V.M., Bykov A.M. Storona zashchity pri zaklyuchenii s prokurorom dosudebnogo soglasheniya o sotrudnichestve // Rossiiskaya yustitsiya. 2010. № 9. S. $18-22$. 